mehreren Exemplaren aufgefunden hat. Diese Art scheint ein Zugvogel zu sein, der nur zeitweilig die nordargentinischen Länder besucht.

Herr Schalow erwähnt zum Schluss, dass im "Aquila“ eine interessante Arbeit über die Zugverhältnisse der südameriknnischen Vögel sich befindet und dass bei Wörlitz ein Aquila pernata geschossen sein soll. Wenn sich dieses Vorkommen bestätigt, so ist es deshalb sehr merkwürdig, weil man bisher nur 4 Fälle kennt, in denen diese Art in Deutschland nachgewiesen ist. Matschie, Schriftführer.

\title{
Bericht über die Januar-Sitzung 1898.
}

Verhandelt Berlin, Montag, den 10. Januar 1898, Abends 8 Uhr im Bibliothekzimmer des Architekten-Vereinshauses, Wilhelmstr. 92 II.

Anwesend die Herren Möbius, Reichenow, Deditius, von Treskow, Grunack, Deichler, Schenkling, von Oertzen, Matschie, Krüger-Velthusen, von Dallwitz (Tornow), Neumann, Pascal, Rörig, Zimmermann (Königsberg i. P.), Nauwerck, Heck, Schalow, Heinroth.

Als Gäste nahmen Teil die Herren Professor Dr. Müllenhoff, Hase, von Brabender, Dr. Freymadl, Staudinger, Dr. von Mathrenthal, Professor Dr. Plate.

Vorsitzender: Herr Möbius. Schriftf.: Herr Matschie.

Herr Schalow begrüsst nach der Eröffnung der Sitzung die anwesenden neu eingetretenen Mitglieder und giebt alsdann einige kurze Bemerkungen über die wichtigsten im Verlaufe des verflossenen Jahres erschienenen Arbeiten auf ornithologischem Gebiete, wobei er besonders die von Mitgliedern der Gesellschaft veröffentlichten Aufsätze berücksichtigt.

Herr Reichenow giebt hierauf einen Bericht über den augenblicklichen Stand unserer Gesellschaft, der günstiger als in irgend einem vorangegangenen Jahre sich gestaltet.

Alsdann bespricht Herr Reichenow einige neu eingegangene und erschienene ornithologische Schriften.

Herr Matschie äussert sich nunmehr über eine sehr interessante Arbeit von H. von Jhering: Über die geographische Verbreitung der Singvögel von S. Paulo (Journ. f. Ornith. 1898 I p. 6-24). H. von Jhering gehört zu denjenigen Zoologen, welche sich mit zoogeographischen Fragen gern beschäftigen. Die Provinz San Paulo hat eine sehr eigentümliche Ornis. Arten, die vom Amazonas und von Bahia bekannt sind, haben hier ihre Südgrenze, wieder andere, welche in dem La-Plata und ParanaLande häufig sind, dehnen ihr Verbreitungsgebiet bis zum Südwesten von San Paulo aus, und endlich giebt es auch Arten, welche nur die Küstenzone von Brasilien bewohnen und entweder 